\title{
Uncertainty and sensitivity analyses in seismic risk assessments on the example of Cologne, Germany
}

\author{
S. Tyagunov, M. Pittore, M. Wieland, S. Parolai, D. Bindi, K. Fleming, and J. Zschau \\ Helmholtz Centre Potsdam, German Research Centre for Geosciences (GFZ), Potsdam, Germany \\ Correspondence to: S. Tyagunov (tyagunov@gfz-potsdam.de)
}

Received: 10 June 2013 - Published in Nat. Hazards Earth Syst. Sci. Discuss.: 9 December 2013

Revised: 25 October 2013 - Accepted: 15 May 2014 - Published: 27 June 2014

\begin{abstract}
Both aleatory and epistemic uncertainties associated with different sources and components of risk (hazard, exposure, vulnerability) are present at each step of seismic risk assessments. All individual sources of uncertainty contribute to the total uncertainty, which might be very high and, within the decision-making context, may therefore lead to either very conservative and expensive decisions or the perception of considerable risk. When anatomizing the structure of the total uncertainty, it is therefore important to propagate the different individual uncertainties through the computational chain and to quantify their contribution to the total value of risk. The present study analyses different uncertainties associated with the hazard, vulnerability and loss components by the use of logic trees. The emphasis is on the analysis of epistemic uncertainties, which represent the reducible part of the total uncertainty, including a sensitivity analysis of the resulting seismic risk assessments with regard to the different uncertainty sources. This investigation, being a part of the EU FP7 project MATRIX (New Multi-Hazard and Multi-Risk Assessment Methods for Europe), is carried out for the example of, and with reference to, the conditions of the city of Cologne, Germany, which is one of the MATRIX test cases. At the same time, this particular study does not aim to revise nor to refine the hazard and risk level for Cologne; it is rather to show how large are the existing uncertainties and how they can influence seismic risk estimates, especially in less wellstudied areas, if hazard and risk models adapted from other regions are used.
\end{abstract}

\section{Introduction}

Following the generally accepted concept of risk, a risk value is determined by considering and combining three main contributing factors: hazard, exposed assets and their vulnerability. Depending on the field of application, different definitions of risk and its constituents can be encountered (e.g. Thywissen, 2006; ISDR, 2009), the most common being that the hazard defines the degree of harmful influence on an exposed system, which, in turn, is characterized on the one hand by the vulnerability (i.e. specifying the damage susceptibility with respect to this type of hazard), and on the other, by the exposed values/assets at risk (i.e. determining the loss potential).

A similar concept is traditionally used for seismic risk assessment as can be found in numerous studies and publications devoted to different aspects of this problem. Usually, seismic hazard estimates, either in the form of ground motion fields from single earthquake scenarios, or in the form of hazard curves from probabilistic seismic hazard assessments, are combined with the vulnerability characteristics of buildings (in the form of damage probability matrices, fragility or vulnerability curves), from which the degree of probable physical (structural) damage to the considered system is calculated. The obtained structural damage estimates are then combined with the exposed asset values (costs) to evaluate the resulting risk (in terms of potential losses, e.g. monetary, human, etc.).

Needless to say, a variety of uncertainties originating from different sources are present at every step of the risk assessment process. All of the individual sources of uncertainty contribute to the total uncertainty, which may be very high and critical within the decision-making context. High uncertainties, for example, can lead to either very conservative and 
expensive decisions, or the perception of considerable risk (e.g. Paté-Cornell, 2002; McGuire, 2008). From the standpoint of a decision maker, when anatomizing the total uncertainty, it is therefore important to identify all uncertainty sources with the view of propagating different individual uncertainties through the computational chain and quantifying their contribution to the total value of risk. This is not a trivial task though, as various uncertainties and errors may originate from different sources due to the natural variability of the phenomena under investigation, incompleteness of input data, inadequacies in the models and methods, etc. (e.g. Douglas, 2007). In fact, it may be simply impossible to identify all uncertainty sources, and even when some (or most) of the sources are identified, there still remains the problem of quantifying their contributions to the total uncertainty.

Considering the taxonomy prevalent in the risk assessment community (e.g. SSHAC, 1997; de Rocquigny, 2012), two different types of uncertainties are usually identified, depending on their nature - namely, "aleatory" and "epistemic". The part of the total uncertainty related to the inherent variability in the behaviour of a system is commonly known as aleatory uncertainty (sometimes referred to as "randomness"). The other part, which is related to the state of knowledge about the system under consideration, is known as epistemic uncertainty. It is important to distinguish between these, in that the epistemic uncertainty can be reduced by collecting additional relevant information and improving the state of knowledge, while the aleatory uncertainty is not reducible and, in principle, cannot be dealt with using deterministic approaches. However, it should also be kept in mind that a given source of uncertainty cannot often be neatly separated into these types, with many sources containing elements of both.

While solving problems of seismic risk assessment and mitigation, researchers and decision makers face both aleatory and epistemic uncertainties. For example, on the one hand, due to the stochastic nature of seismic phenomena, the exact location, magnitude and time of future seismic events are not predictable, representing an aleatoric part of the uncertainty. On the other, the spatial distribution of potential seismic source zones, the maximum possible earthquake magnitude and the recurrence rates for events of different magnitudes are continuously being investigated and new models are being developed and updated on the basis of the current and new knowledge to reduce the epistemic part of the uncertainty in future earthquakes. Another example, considering the prediction of seismic effects and the seismic performance of existing buildings, involves the natural variability of soil conditions, inherent scattering of ground motions (including both the level and frequency content), stochastic ground-structure interactions and the structural response of buildings, which constitute an aleatoric (not reducible) part of the uncertainty, while the proper choice of ground motion prediction equations, geotechnical and microzonation studies in an area, detailed building inventories and the develop- ment of building-type-specific vulnerability functions would reduce the epistemic part of the uncertainty.

A better understanding of the mechanisms of the origin and propagation of uncertainties would allow improvements in the methods of risk assessment and the increased efficiency of risk reduction strategies. Keeping this objective in mind, uncertainty reduction efforts should be aimed at the reducible (epistemic) part of the total uncertainty, which is related, first of all, to the quality of the available input data and, secondly, to the quality of the used models. While, by definition, the level of epistemic uncertainty can be reduced and ideally should be eliminated, at the present time considerable epistemic uncertainties commonly and unavoidably exist in hazard and risk models. It is another matter that the level of epistemic uncertainty may be different in different regions (well- or little-studied areas). Consideration of this problem is one of the tasks of the current study.

Uncertainty and sensitivity analyses are important tools in risk modelling. Uncertainty analysis is defined as a tool to quantify the uncertainty in the model predictions, and sensitivity analysis is the complementary tool used to study how the uncertainty in the model output can be apportioned to different sources of uncertainty in the model input (Saltelli et al., 2008). These tools are complementary and offer greater value when used together.

Different methods are used for the analysis of uncertainties, inter alia in the seismic hazard and risk assessments, e.g. Monte Carlo methods (e.g. Cramer et al., 1996; Smith, 2003; Zentner et al., 2008), first-order, second moment method (e.g. Baker and Cornell, 2008; Bradley and Lee, 2010), Bayesian methods (e.g. Li et al., 2010; Bayraktarli et al., 2011), fuzzy logic methods (e.g. Karimi and Hüllermeier, 2007; Zlateva et al., 2011; Buratti et al., 2012), and logic tree methods (e.g. Grünthal and Wahlström, 2001; Bommer et al., 2005; Scherbaum et al., 2005). In addition to the references mentioned, an overview of existing approaches, considering the advantages and shortcomings of different methods of uncertainty treatment, including examples of practical applications, can be found in Wen et al. (2003), Nadim (2007), Wang et al. (2009), and Aven and Zio (2011). Probably the most widely used uncertainty treatment methods in seismic hazard and risk calculations are Monte Carlo simulation techniques and logic trees, their modifications and their combinations. The logic trees, in particular, are often considered as the state-of-the-art tool to quantify and incorporate epistemic uncertainty (Bommer and Scherbaum, 2008). As well, in our study, which focuses on the analysis of epistemic uncertainties, we use the logic tree approach, which is useful for both uncertainty evaluation and parametric sensitivity analysis.

Numerous publications devoted to different aspects of uncertainty and sensitivity analyses in seismic risk assessments (e.g. Crowley et al., 2005; Bazzurro and Luco, 2005; Molina and Lindholm, 2007; Padgett and DesRoches, 2007; Liel et al., 2009; Wesson et al., 2009; Sokolov and Wenzel, 2011; and many others) emphasize both the importance and 
complexity of the problem. Most often, however, in the available literature, consideration is given separately to the individual risk components, for example, hazard or vulnerability, whereas a proper holistic approach would require analysing the whole chain of the risk assessment, propagating uncertainties from the input source to the outcome result, and evaluating their contribution to the total uncertainty.

With the view of filling in the existing knowledge gap, our study aims at the consideration of different uncertainties associated with the hazard, vulnerability and loss components within the context of an urban environment. The emphasis is placed on the analysis of epistemic uncertainties, representing the reducible part of the total uncertainty (errors in the input parameters and the models), including the sensitivity analysis of the resulting seismic risk assessments with regard to the different sources of uncertainties. In particular, the study aims to shed light on how high the uncertainty level can be in little-studied areas, where hazard and risk models are based on data adapted from other regions of the globe, and how the uncertainties can influence the hazard and risk results.

Keeping the above-mentioned purposes in mind, it seems reasonable to consider an area where some reliable results are already available. We therefore conduct our study on the case of the city of Cologne, Germany, taking advantage of the fact that this area has been a test case for several previous seismic hazard and risk assessment and research studies (e.g. Allmann et al., 1998; Grünthal and Wahlström, 2006; Grünthal et al., 2006; Schwarz et al., 2004a, b, 2006; Tyagunov et al., 2004, 2006a, b; Parolai et al., 2007; Daniell and Wenzel, 2011), where substantial results have been obtained, representing an important basis for the further development of risk assessment methodologies, including, in particular, uncertainty analysis.

\section{Study area}

The city of Cologne is an appropriate area for the goals of this investigation. Firstly, there is substantial groundwork in terms of results from previous studies, which can be considered as a benchmark for comparison. Secondly, considerable levels of uncertainty in the different risk components still exist, and their contributions to risk have not yet been evaluated.

Cologne is one of the largest cities in Germany, with more than one million inhabitants. It is a major industrial, financial and cultural centre of the country, and the Rhine-Ruhr metropolitan region. Geographically, the city is situated in the Lower Rhine Embayment, which belongs to one of the most seismically active regions in western and central Europe (Rosenhauer and Ahorner, 1994). In the past, damaging earthquakes have occurred in the area (Grünthal et al., 2009). One of the strongest recorded events in this region was the $M_{\mathrm{w}}=5.91756$ Düren earthquake, with an epicentral intensity of 8 and an estimated intensity in Cologne of
6.5. The last strong event in the area was the $M_{\mathrm{w}}=5.31992$ Roermond earthquake, whose epicentre was located in the Netherlands at a distance of about $80 \mathrm{~km}$ from Cologne, resulting in an intensity in the city of about 5 . The total level of losses of the Roermond earthquake (affecting distances up to $300 \mathrm{~km}$ away) was estimated to be about EUR 128 million, while the losses in Germany were estimated to be about EUR 36 million (Bertz, 1994).

In the recent years, several publications taking into consideration important findings of palaeoseismological investigations in the region (e.g. Camelbeeck et al., 2000, 2007; Atakan et al., 2001; Schmedes et al., 2005; Hinzen and Reamer, 2007; Verbeeck et al., 2009) have estimated a $M_{\max }$ for earthquakes in the Lower Rhine Embayment at a level of up to 7.0. For the Erft fault system west of Cologne, considered to be one of the most important active faults in the area, Vanneste et al. (2013) suggest a $M_{\max }$ of 7.1. Although the recurrence interval of such events is in terms of several thousand years, obviously earthquakes represent a considerable threat for this highly populated region, requiring thorough seismic risk assessment and mitigation.

Regarding seismic hazard for Cologne, the well-known results of a probabilistic seismic hazard assessment (Grünthal and Wahlström, 2006) show, in particular, the hazard (mean value) for the centre of the city to be of the order of $I=6.9$ for a $10 \%$ probability in 50 years (corresponding to a mean return period of 475 years) and $I=7.7$ for a $2 \%$ probability in 50 years (return period of 2475 years).

The area of the Cologne community, which currently encompasses over 405 square kilometres, is divided into two parts by the Rhine River and administratively consists of nine districts. The built-up area of the city comprises about $45 \%$ of the total area, and about two thirds of the total building stock consists of residential buildings. After World War II, during which Cologne was heavily damaged, the built environment of the city (about $95 \%$ ) was almost fully reconstructed. Nowadays, the building stock of Cologne is represented by different types of structural systems, including masonry, reinforced concrete, steel and timber structures, although the residential building stock of the community is dominated by masonry buildings. Some details about the composition of the building stock of the city can be found in the publications of Schwarz et al. (2004a, b, 2006), based on the outcomes of the DFNK (Deutsches Forschungsnetz Naturkatastrophen - German Research Network Natural Disaster) project, within which Cologne was a case study.

\section{Approach description}

The goal of seismic risk analyses for built-up areas is to quantify the level of potential damage and losses due to probable future earthquakes. For the purposes of decision making, the quantitative risk estimates should include uncertainty bounds. Therefore, to calculate seismic risk, all of the 
contributing components, including seismic hazard, the built environment and its seismic vulnerability, as well as the uncertainties associated with these components, should be evaluated. The calculated risk estimates are presented in terms of risk curves showing level of losses for different occurrence probabilities (average return periods).

\subsection{Hazard modelling}

At the stage of probabilistic seismic hazard analysis, the probability of exceeding various levels of ground shaking at a site (or a map of sites) is quantified given all possible earthquakes in the area. The hazard level can be quantified in terms of peak ground accelerations, spectral accelerations or macroseismic intensities. The use of each option depends on the purpose of the study. In particular, the choice of the spectral approach would be an advantage for a single site/building, or for those areas where both detailed information about the hazard (including microzonation) and building inventory data are available. Otherwise, in particular for areas of low and moderate seismicity lacking instrumental records, as well as for communities lacking detailed inventory data, the intensity-based approach would be advisable (Musson, 2000).

In our study, the seismic hazard is analysed in terms of macroseismic intensities with respect to the European Macroseismic Scale (EMS-98, Grünthal, 1998), while at the same time assuming equivalency of the level of seismic impact with other scales (in particular, MSK and MMI).

\subsection{Exposure and vulnerability modelling}

For damage and risk analyses, all exposed assets (buildings, contents, infrastructure, population, etc.) and their spatial distribution with regards to the hazard distribution should be analysed. For the purposes of this study, we consider only primary economic losses due to the structural damage to the residential building stock. As a rule, residential buildings are dominant in the total building stock and, therefore, such an approach is widely used for assessing seismic risk in urban areas.

While collecting the inventory data and modelling the existing residential building stock of the area, the buildings are analysed from the point of view of their vulnerability i.e. their seismic performance and potential degree of structural damage under a specific level of ground motion) and with respect to assets (describing the exposed value of construction costs and potential monetary losses due to the structural damage to the buildings).

Seismic vulnerability modelling in this study is based on the vulnerability classification of EMS-98, where six vulnerability classes are introduced, denoted alphabetically from A (highest vulnerability) to F (lowest vulnerability). According to EMS-98, different types of buildings are classified into different vulnerability classes, depending, first of all, on the building material and the type of structure, while also taking into consideration other factors such as construction and architectural features, quality and workmanship, age and state of preservation, etc., which may affect the seismic performance of the buildings. Considering such information for a single building or a group of buildings (representing a part of the building stock), and using the vulnerability table of the EMS-98, the most probable vulnerability class or a range of probable vulnerability classes can be identified and assigned to a building, group of buildings or district.

Vulnerability modelling of built-up areas should take into account the fact that the built environment is usually composed of different types of buildings. Therefore, for damage and risk analyses it is necessary to construct vulnerability composition models that properly reflect the real composition and spatial distribution of different types of buildings in the area under consideration. Vulnerability composition is understood as the percentage of buildings corresponding to the different EMS vulnerability classes within a computational cell.

\subsection{Damage and risk assessment}

For damage and risk analyses, the constructed vulnerability composition models are combined with the estimates of seismic hazard distribution. The level of structural damage to buildings of different vulnerability classes can be estimated by the use of damage probability matrices or fragility curves that describe the probability of different damage levels as a function of the intensity of ground shaking. The damage probability matrices, which were constructed following the guidelines of the EMS-98, are taken from Tyagunov et al. (2006b). The range of damage states is described in terms of the damage classification of EMS-98 (Grünthal, 1998), where there are five possible damage states (grades) of the affected structures, ranging from "negligible damage" to "total destruction". While analysing the level of structural damage to buildings, we also include the state of "no damage", resulting, therefore, in six possible states of an affected system being considered $\left(\mathrm{D}_{0}-\right.$ no damage, $\mathrm{D}_{1}-$ negligible to slight damage, $D_{2}$ - moderate damage, $D_{3}-$ substantial to heavy damage, $\mathrm{D}_{4}$ - very heavy damage, $\mathrm{D}_{5}$ - destruction).

Only direct monetary losses due to structural damage to residential buildings are taken into account in this study. The level of losses is estimated in terms of mean damage ratio (MDR), determined as the cost of repair over the total cost of the damaged buildings, as well as in monetary terms, taking into consideration the estimated construction costs of residential buildings in Germany (Kleist et al., 2006).

\subsection{Uncertainty analysis}

Within this study we consider a range of epistemic uncertainties associated with hazard, vulnerability and loss modelling. Uncertainties in hazard calculations are mainly associated 


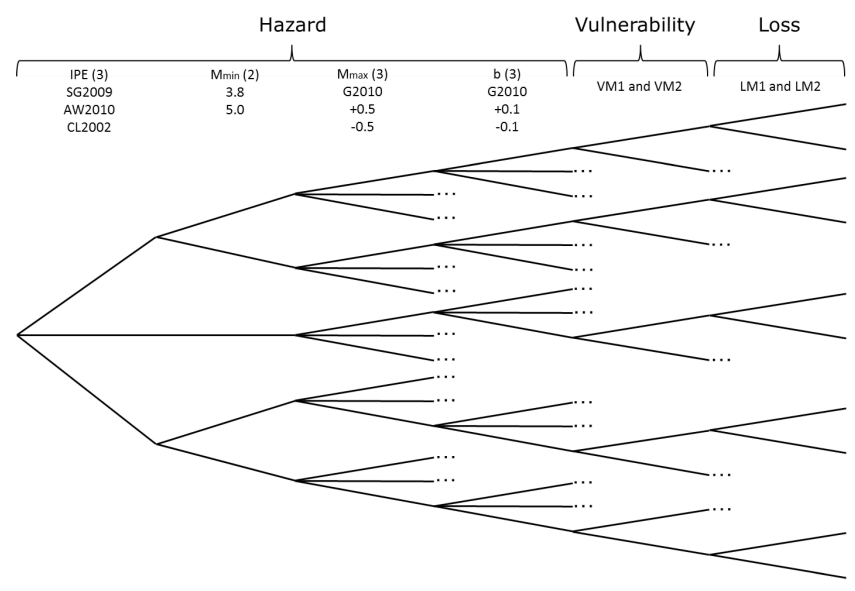

Figure 1. Logic tree scheme and number of input parameters for the different modules: Hazard: intensity prediction equations (IPEs) 3, $M_{\min }-2, M_{\max }-3$, Gutenberg-Richter $b-3$, Vulnerability: 2 models, Loss: 2 models. Equal weights are assigned to all the branches of the logic tree (more details in the text).

with earthquake occurrence (including location, magnitude and frequency) and ground motion intensity prediction (including intensity attenuation and local effects). Here we consider uncertainties related to the errors in determining the maximum earthquake magnitude, occurrence rate and selection of the attenuation relationships.

The main uncertainties in exposure (building stock) modelling are associated with the spatial distribution of different types of buildings and the assessment of their characteristics related to both vulnerability and costs. These are epistemic uncertainties due to the incomplete inventory data and limited knowledge of the structural features of the buildings. In this study we consider the uncertainties associated with the modelling of the building stock. Regarding the loss assessment, as mentioned above, the risk level is evaluated in terms of mean damage ratio and direct monetary losses. In so doing, we consider uncertainties associated with selection of loss ratio functions, i.e. the relationships between the damage state of affected buildings (described by the structural damage grade) and the corresponding level of direct losses.

As a tool for analysing the epistemic uncertainties associated with the parameters and models used in the hazard and risk analyses, we use the logic tree approach. Schematically, the logic tree structure, describing the three different modules of risk analysis (hazard, vulnerability and loss) and considered uncertainties associated with the input parameters, is shown in Fig. 1, and will be described in detail in the following sections. It should be mentioned that the authors are aware of possible larger ranges and greater variability in the existing uncertainty sources than have been taken into consideration in this work. However, we are at this time purposely restricting the number of branches, keeping in mind the practical implementation of the parametric analysis.

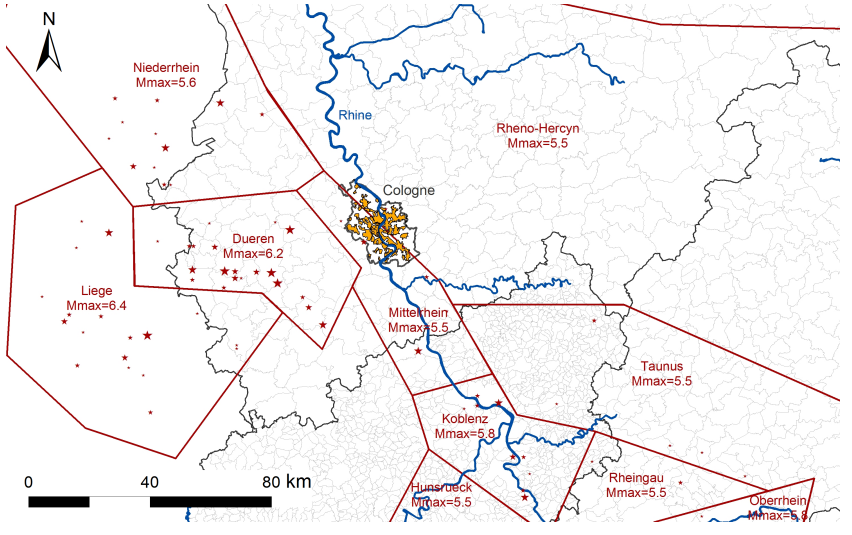

Figure 2. Seismic source zones (SSZs) around Cologne (according to Grünthal et al., 2010). The stars show the epicentres of past earthquakes in the area (from the CENEC earthquake catalogue, Grünthal et al., 2009). The grey lines show the administrative boundaries. The built-up area in Cologne is shown in yellow.

\section{Seismic hazard modelling}

The current study is by no means intended to reconsider or refine the existing hazard estimates for the study area. The main point is rather to use the advantage of the elaborated hazard assessment (which can be considered to be a benchmark) for uncertainty and sensitivity analyses. In so doing, we can see how the uncertainties can influence the hazard and risk estimates in less well-studied areas that lack the regional data and therefore use hazard and risk models from other regions.

For the hazard calculations, we use the OpenQuake software, being developed within the framework of the GEM (Global Earthquake Model) initiative (www. globalquakemodel.org). OpenQuake is an open source software tool for seismic hazard and risk analyses which follows different approaches, both probabilistic and deterministic. In the present study, we use the option of Classical Probabilistic Seismic Hazard Analysis, following the classical integration procedure (Cornell, 1968; McGuire, 1976) as formulated by Field et al. (2003). The computational workflow of the procedure includes the logic tree processor combined with a Monte Carlo sampler and provides a tool for analysing epistemic uncertainties. A detailed description of the software, including the scientific background and instructions for its implementation, can be found in the OpenQuake Book and OpenQuake Manual (Crowley et al., 2011a, b).

The hazard calculations are implemented in terms of seismic intensities. The initial input data for these hazard calculations, including the seismic source zone (SSZ) model for the area around Cologne (Fig. 2) and the seismicity parameters, are from Grünthal et al. (2010), while the intensity-attenuation model is taken from Stromeyer and Grünthal (2009). 
Regarding the uncertainty analyses, we assume that the original input data and models are as equally uncertain as the data and models drawn from other sources. This assumption can reflect a quite realistic situation in little-studied areas that lack reliable regional data. In such a case, the logic tree approach can serve as a useful tool for analysing the possible influence of different models and parameters.

Among the most critical input parameters for hazard calculations, we consider the maximum possible magnitude, seismicity recurrence parameters and attenuation relationships. Using the original values (taken from Grünthal et al., 2010, and referred to as G2010) for one of the branches of the logic tree, we introduce epistemic uncertainties to other branches by manipulating the above-listed parameters as described below.

The maximum possible magnitude is one of the key parameters responsible for the level of seismic hazard. An underestimation of its value, for example, may cause tragic consequences in the affected area, while an overestimation of $M_{\max }$ would lead to undue conservatism in engineering decisions (and increased construction costs). In the current study, we consider a relative error of 0.5 magnitude units, adding or subtracting this increment with respect to the original magnitude estimate (G2010). This is done for all the SSZs in the area under study, although it would be worthwhile to also consider the possible influence of the relative error that applies to only one of the zones, namely the one that controls the level of hazard in the area of interest. In our case, this is the Düren SSZ (Fig. 2), where the earthquake of 1756 (one of the strongest seismic events ever recorded in this region) occurred.

Another considered parameter is the $b$ value of the Gutenberg-Richter relationship, which describes the slope of a graph of the number of events for a given magnitude, i.e. it describes the proportion of smaller and larger magnitude events. In this study, we also consider the possible influence of a relative error of 0.1 (assumed to be a typical error in the $b$ value), adding (or subtracting) this increment to (or from) the original value (G2010) of the $b$ value parameter.

As for the set of the intensity attenuation relationships, we consider one of the regional relationships derived using two different regression techniques presented in Stromeyer and Grünthal (2009). Those two relationships provide very close estimates; therefore for the hazard and risk calculations and comparison of the results shown below only one of them was used - namely, the relationship based on the chisquare regression method. In addition, we consider the relationship of Chandler and Lam (2002), developed for similar tectonic conditions in China, and the relationship of Allen and Wald (2010), which was developed for global applications. In the following these three intensity prediction equations are referred to as SG2009, CL2002 and AW2010, correspondingly.

In addition to the parameters listed above, we consider two different values of the parameter $M_{\min }$. The value of

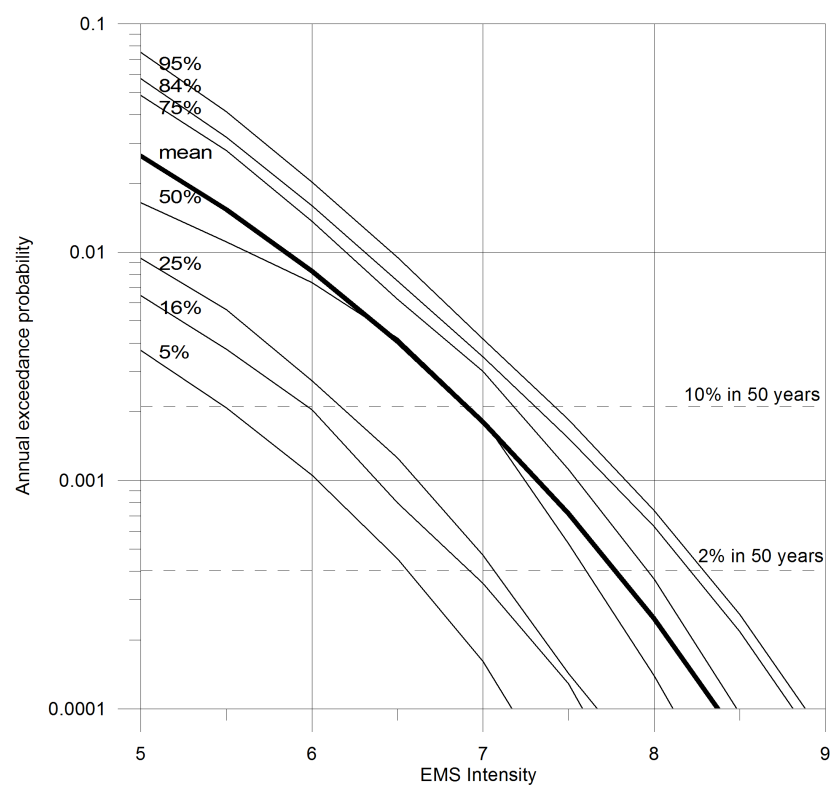

Figure 3. Calculated mean and quantile hazard curves, considering the whole range of the input parameters of the hazard part of the logic tree (Fig. 1).

$M_{\min }=3.8$ is taken following the regional model of Grünthal et al. (2010), whereas the value of $M_{\min }=5.0$ is the lower limit of the intensity prediction equation based on the global data set (Allen and Wald, 2010). Therefore, the estimates obtained with the use of the attenuation relationship of AW2010 are calculated for the parameter $M_{\min }=5.0$ only, while the results obtained using the attenuation relationships of SG2009 and CL2002 are calculated for the values of both $M_{\min }=3.8$ and $M_{\min }=5.0$.

Correspondingly, the hazard part of the logic tree (Fig. 1) is composed of 45 branches, consisting of three branches of maximum magnitude, two branches of minimum magnitude, three branches of $b$ value and three branches of intensity prediction equations. For the purposes of the study (especially bearing in mind the realistic situation in little-studied areas), we assigned equal weights to all of the branches of the logic tree.

The calculated hazard curves are shown in Fig. 3, including the mean and quantiles of 5, 16, 25, 50 (median), 75, 84 and $95 \%$. These curves aggregate different uncertainties and show a considerable scatter of estimates. One can see that the level of uncertainty in hazard estimates, obtained using the whole family of the considered input parameters, can reach two intensity degrees within the range of 5 to $95 \%$ quantiles (covering $90 \%$ of calculated intensities) and about one intensity degree within the interquartile range. At the same time, the mean estimates show a good agreement with the mean hazard estimates of Grünthal and Wahlström (2006), i.e. $I=6.9$ with a $10 \%$ probability in 50 years and $I=7.7$ with a $2 \%$ probability in 50 years (these 
probability levels are highlighted in Fig. 3). The range of uncertainties, however, is larger than those estimated in Grünthal and Wahlström (2006). Such considerable difference can be explained, first of all, by the use of the intensity attenuation relationships adapted from other regions. More detailed consideration to these aspects will be given below, in the section dealing with the sensitivity analysis.

\section{Modelling of the existing building stock}

An important step in risk assessment studies for built-up areas is the selection of an appropriate computational grid, which, obviously, depends on the scale of the study area and the available information required for the spatial modelling of vulnerability and the assets at risk (built environment, population, etc.). In the present study, we consider the city scale, as it is commonly adopted within the MATRIX project (in this context, it means that the risk for the whole city is characterized by a single set of risk curves, spatially referred to the city centre).

For the building stock of an urban area, different sources of information and ways of constructing the spatial model of the built environment can be used. For example, the modelling can be based on statistical information available from the municipal authorities or specialized agencies. In this case, the computational grid is constructed in terms of administrative boundaries (postal code zones, city districts or quarters) and the vulnerability composition models for the grid cells are created by combining available statistical data about the building stock with engineering models for the different building types. At the same time, nowadays advanced satellite- and ground-based remote sensing techniques are widely used for the spatial modelling of built-up areas and they can serve as a rapid and efficient tool for collecting data for risk assessment (Taubenböck et al., 2012; Wieland, et al., 2012).

Needless to say, the modelling of the building stock is associated with different uncertainties. Therefore, the assorted models constructed following the various approaches and based on information obtained from independent sources can represent additional branches of the logic tree for the damage and risk calculations and uncertainty analyses.

Below are described the two vulnerability models considered in this study. The first vulnerability model (VM1) for Cologne represents the whole city as one cell. Such an approach can be used for studies over regional or national scales, as well as for rough estimations of risk for those urban areas lacking detailed information about the spatial distribution of buildings. This model was constructed following the approach described in Tyagunov et al. (2006a), where for different communities of Germany, the vulnerability composition models in terms of the EMS vulnerability classes were developed using statistical information from the INFAS database (2001). In the current study, we use an updated IN-

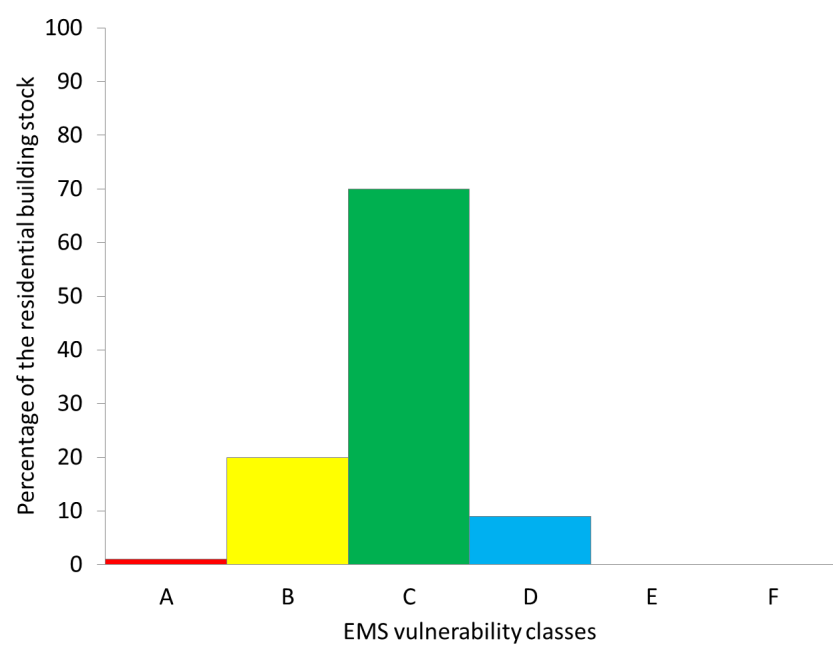

Figure 4. Vulnerability composition model of the residential building stock of Cologne as a percentage of the different vulnerability classes of EMS-98 (based on the INFAS database, 2010).

FAS database (2010). A comparison of the data shows that over the past decade, the number of buildings in Cologne grew by about 10000 and in 2010 exceeded 160000 . At the same time, having analysed the change in the proportional composition of the different types of buildings, we in fact found no significant changes in terms of seismic vulnerability composition, despite a slight change in the proportion of the different types of buildings. In other words, there is no considerable difference between the two vulnerability composition models (in terms of structural vulnerability) for Cologne based on the two data sets of 10-year difference. For details about the vulnerability modelling approach (describing the procedure of data processing and converting the building types into the vulnerability classes), we refer the reader to Tyagunov et al. (2006a, b). The vulnerability composition model constructed for the residential building stock of Cologne as a whole (VM1), using the INFAS database (2010), is presented in Fig. 4.

Construction of the second vulnerability model (VM2) follows the approach of Wieland et al. (2012). The territory under study is divided into a grid of cells based on a stratification of the built-up area of Cologne into sub-areas (called "strata") that are relatively homogeneous in terms of their predominant building types. The stratification is based on a semi-automated processing of medium-resolution satellite images (Landsat) covering the area of the city. The images are first automatically segmented into small regions, which appear to be relatively homogeneous in terms of their spectral response. This operation reduces the complexity of the image, by clustering the original image pixels into "superpixels". Super-pixels can thus be referred to as regions of the image that are simple enough to be considered basic components and can provide additional geometrical, colour and texture features with respect to a single pixel. 


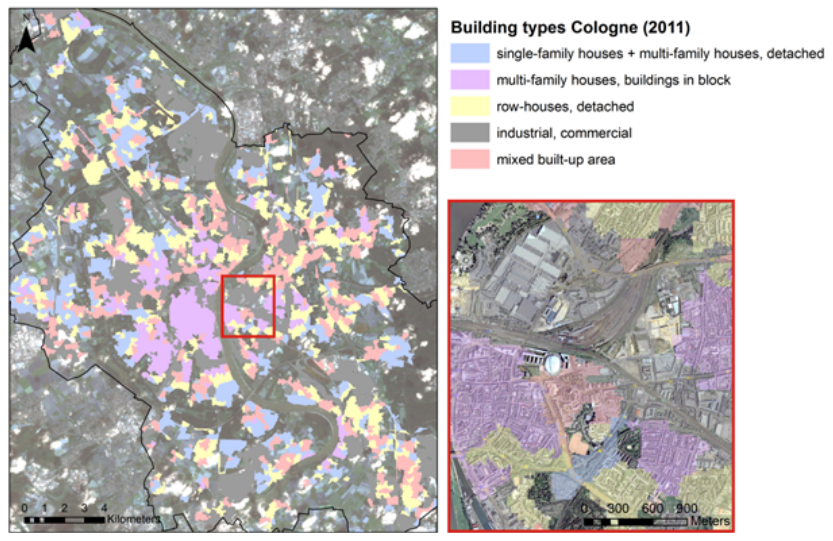

Figure 5. Building type stratification of the study area of Cologne: (a) superimposed on input Landsat image and (b) a magnification superimposed on Google Earth imagery.

The segmented regions are then selectively merged together using a statistical learning machine. The learning machine clusters together the super-pixels by labelling them according to a manually selected training set. The labels describe different land-use/land-cover attributes (in this case, the different predominant building types). The classification scheme for identifying the predominant building types of the study area has been adjusted based on an existing building typology for Germany (Deutsche Gebäudetypologie, 2005), and the experiences described in Schwarz et al. (2006) based on a survey of 800 buildings in Cologne. A set of 75 training instances has been derived through visual satellite and ground-based image interpretation to train the learning machine. Assessing the accuracy of the derived products by a set of 100 independently sampled reference instances provided an overall accuracy of $78 \%$ and a kappa coefficient of 0.74 for the building type's classification. Details of the approach are described in Wieland et al. (2012) and the results for the area of Cologne are shown in Fig. 5.

The procedure of building inventory data collection is based on an omnidirectional camera survey and a rapid visual screening (RVS) of buildings. The camera survey was conducted along pathways optimized in such a way as to cover those areas of the city with different building types, as described above. Therefore, for each stratum, a representative sample of buildings was captured by the omnidirectional images. Building footprints for sampling have been derived from the cadastral map of Cologne (Stadt Köln, 2012). The vulnerability evaluation of the buildings included both in situ field inspections using a RVS procedure and the analysis of the image data obtained during the camera survey. The classification is in accordance with the definitions of the EMS-98 vulnerability table.

The inventory database being developed for the area includes the following parameters that are used for seismic vulnerability assessments: building use, material of bearing
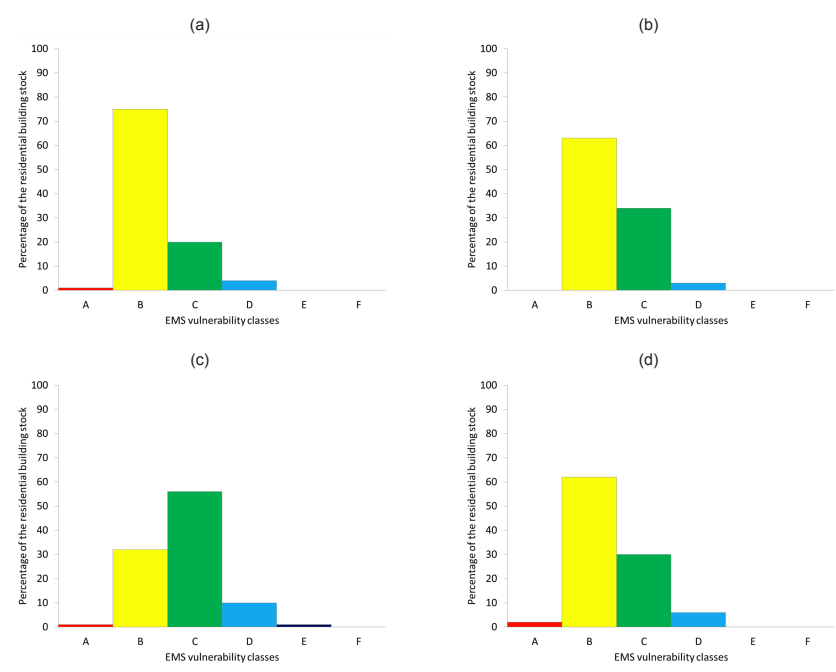

Figure 6. Vulnerability composition models (as a percentage of the vulnerability classes of EMS-98) for the classified urban typology strata of Cologne as outlined in Fig. 5: (a) mixed built-up area; (b) row houses, detached; (c) multi-family houses, buildings in blocks; (d) single-family houses and multi-family houses, detached.

structures, number of floors and height, roof type and presence of an attic floor, irregularity in the plan or elevation, presence of possible pounding effects, etc. The procedure of collecting the data and assessing the vulnerability includes a degree of belief to be used for further damage and risk analyses, including uncertainty quantification.

The vulnerability composition models formulated in terms of the EMS vulnerability classes (on the basis of the procedure and data described above) for the classified urban strata of Cologne are presented in Fig. 6.

Combining the vulnerability composition models with the damage probability matrices (fragility curves) available for the different EMS vulnerability classes, we can construct the aggregated damage probability matrices (fragility curves) for all the computational cells, which are, subsequently, used for the structural damage assessment.

The two vulnerability models (VM1 in Fig. 4 and VM2 in Fig. 6) represent two branches of the logic tree, as shown in Fig. 1.

\section{Structural damage assessment}

The state of the affected building stock can be described in the form of the distribution of the damage grades outlined above (in increasing amount of damage from $\mathrm{D}_{0}$ to $\mathrm{D}_{5}$ ). Mean damage distribution diagrams, corresponding to the two employed vulnerability models, are shown in Fig. 7 for different levels of ground shaking intensity. The estimates for vulnerability model 1 (VM1) are shown in dark grey, and for the vulnerability model 2 (VM2) in light grey. 

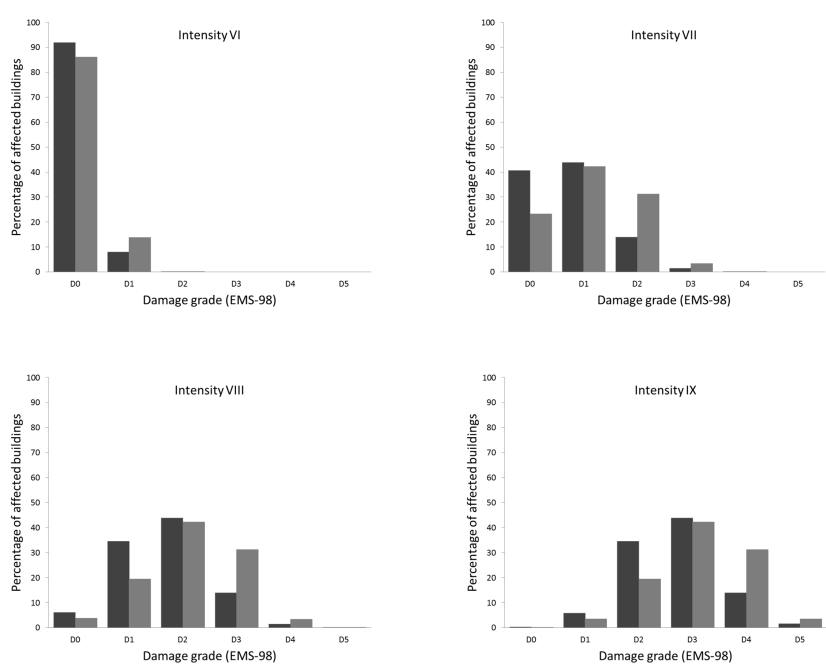

Figure 7. Structural damage distribution diagrams for the two vulnerability models for different levels of EMS intensity (VM1 - dark grey, VM2 - light grey).

Another possible way of characterizing the level of structural damage of a family of affected buildings is by estimating the mean damage grade (MD), a parameter widely used within the earthquake engineering community.

The calculated damage probability estimates obtained by the use of all the hazard curves (Fig. 3) and the two vulnerability models (Figs. 4 and 6 ) are presented in Fig. 8. To show the difference between the two models, the mean damage curves are shown separately for the two vulnerability models (the solid line corresponds to VM1, the dashed line to VM2), while the curves corresponding to the 5 and 95 percentiles represent the uncertainty.

A comparison of the calculated results presented in Figs. 7 and 8 shows that VM2 gives, in general, higher damage estimates than those from VM1. For instance, the mean values of MD for intensity VII are 0.76 (VM1) and 1.15 (VM2), and for intensity VIII they are 1.70 (VM1) and 2.11 (VM2). It should be mentioned that the mean values for both models are comparable with the estimates of Schwarz et al. (2006), where the level of mean damage grade for Cologne for an intensity $I=$ VIII was estimated to be between 1.7 and 1.9. However, we should keep in mind that mean estimates alone are inadequate for the purposes of decision making and that the existing uncertainties should be taken into account. Considering the range of uncertainty estimates presented in Fig. 8, we can see that errors in the vulnerability models may be critical for decision making.

\section{$7 \quad$ Loss modelling}

Combining the structural damage estimates with the asset data values, a seismic loss assessment can be performed and, depending on the aim of the study, the risk can be evaluated

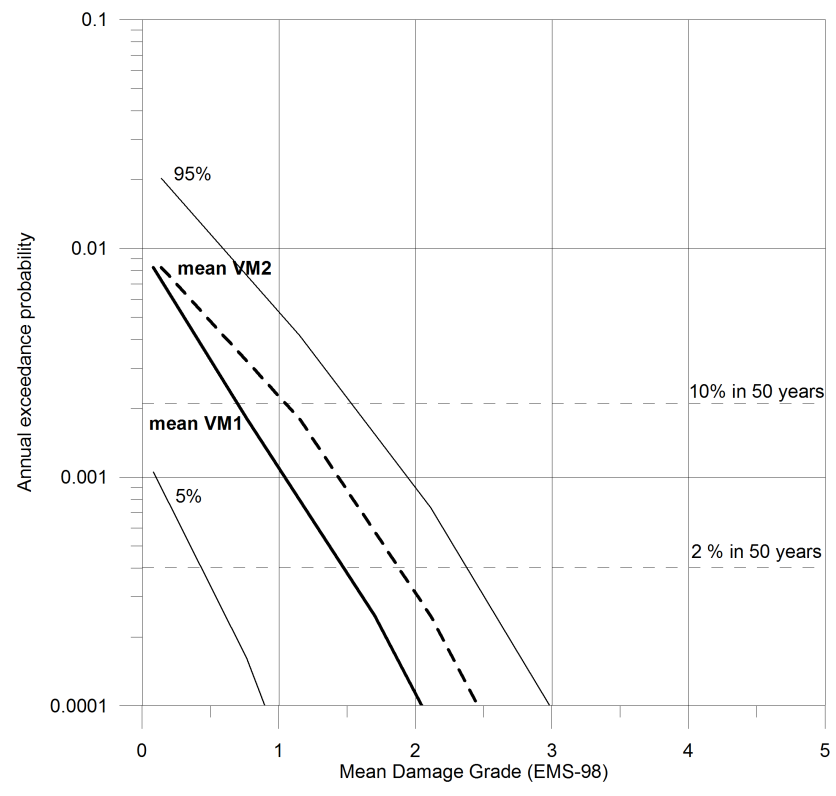

Figure 8. Structural damage probability estimation (in terms of mean damage grade) for the residential building stock of Cologne. The solid line corresponds to the mean estimate for VM1, the dashed line for VM2. The uncertainty bounds (5 and 95\%) correspond to the total uncertainty.

in terms of either monetary or human losses. At the same time, the level of probable losses can be described in terms of the mean damage ratio (expressed as a percentage of replacement value). For this purpose, the corresponding loss ratio functions should be assigned. The loss ratio, which is sometimes referred to as the "cost ratio", "damage ratio" or "damage factor", is defined as the ratio resulting from the cost of repair (depending on the specific damage state) divided by the cost of replacement of a damaged structure.

A variety of different loss ratio functions can be found in the literature (e.g. Whitman and Cornell, 1976; Hwang et al., 1994; Miyakoshi et al., 1997; Kircher et al., 1997; Tyagunov et al., 2006a; Chen and Sun, 2008). One must, however, remember that seismic performance of different building types, including the structural damage mechanism, differs considerably, hence such damage-loss relationships are buildingtype specific and depend upon the peculiarities of regional construction practices. Therefore, for practical applications, one should bear in mind that the use of different loss models, especially adapted from other regions, can introduce additional uncertainties into the loss estimation chain. In this study, we employ two different loss models, which are presented in Table 1.

Both loss models are based on the five-grade classification of possible damage states; however, Table 1 shows considerable differences between these models. As mentioned above, the differences in the loss ratio estimates can be explained by the peculiarities of the regional building 
Table 1. The loss models employed in this study.

\begin{tabular}{rrrrrr}
\hline \multirow{2}{*}{$\begin{array}{c}\text { Damage } \\
\text { grade }\end{array}$} & $\begin{array}{c}\text { Loss model 1 } \\
\text { (Tyagunov et al., 2006a) }\end{array}$ & & \multicolumn{2}{c}{$\begin{array}{c}\text { Loss model 2 } \\
\text { (Hwang et al., 1994) }\end{array}$} \\
\cline { 5 - 6 } & $\begin{array}{r}\text { Loss } \\
\text { ratio (\%) }\end{array}$ & $\begin{array}{r}\text { Central } \\
\text { value }(\%)\end{array}$ & & $\begin{array}{r}\text { Loss } \\
\text { ratio }(\%)\end{array}$ & $\begin{array}{r}\text { Central } \\
\text { value }(\%)\end{array}$ \\
\hline 0 & 0 & 0 & & 0 & 0 \\
1 & $0-1$ & 0.5 & & $0.05-1.25$ & 0.3 \\
2 & $1-20$ & 10 & & $1.25-7.50$ & 3.5 \\
3 & $20-60$ & 40 & & $7.50-20$ & 10 \\
4 & $60-100$ & 80 & & $20-90$ & 65 \\
5 & 100 & 100 & & $90-100$ & 95 \\
\hline
\end{tabular}

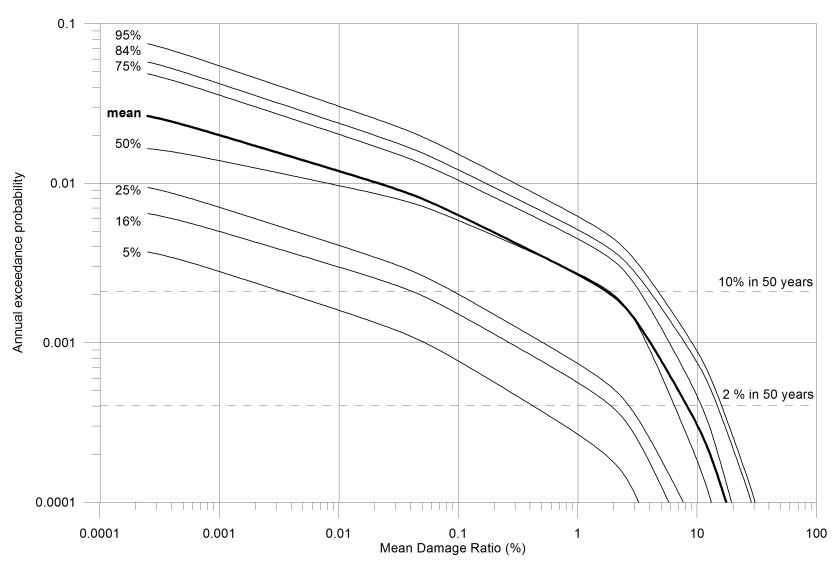

Figure 9. Calculated mean and quantile risk curves (in terms of MDR) for the whole range of the logic tree branches (Fig. 1).

typologies. Generally speaking, the loss model 1 (LM1), which was developed on the basis of the damage classifications of EMS-98 (Tyagunov et al., 2006a), may be considered consistent with the European building typology, whereas the loss model 2 (LM2), which was developed for the estimation of seismic damage and repair costs of buildings in the University of Memphis, Tennessee (Hwang et al., 1994), can be more appropriate for the building typology of the USA. Therefore, such regional peculiarities should be taken into consideration when selecting the proper loss models for risk assessments. In our study, the loss models LM1 and LM2 represent two different branches of the logic tree (Fig. 1).

\section{Seismic risk and uncertainty}

Following the computational algorithm described above and in accordance with the logic tree structure (Fig. 1), we calculated the risk for all the considered branches of the logic tree. The obtained seismic risk curves in terms of MDR are presented in Fig. 9. The presented estimates include the mean curve as well as the curves corresponding to the 5, 16, 25, $50,75,84$ and 95th percentiles, which show the overall uncertainties in the seismic risk assessment, including those as-
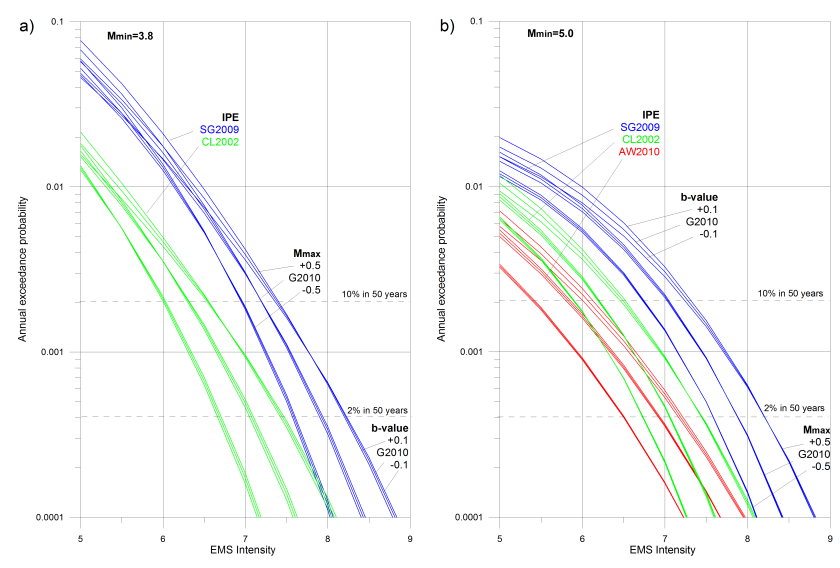

Figure 10. Hazard curves calculated for different combinations of the input parameters: (a) for $M_{\min }=3.8$ and IPE from Stromeyer and Grünthal (2009) and Chandler and Lam (2002), (b) for $M_{\min }=$ 5.0 and all three considered IPE.

sociated with the range of all considered hazard input parameters, vulnerability and loss models.

There is a dual way of understanding and interpreting the presented risk estimates. On the one hand, the curves (corresponding to the different percentiles) indicate the cumulative probability associated with any particular damage level; on the other hand, they show the range of uncertainty in damage estimates at different probabilities (corresponding to different average return periods). One can see that the uncertainty range in Fig. 9 is very large. While, by itself, uncertainty does not necessarily indicate increased or decreased level of risk, obviously it can significantly impact upon the decisionmaking process, when decision makers will strive to reduce both the risk level and uncertainty level. It is important, therefore, to identify and quantify the contribution of individual components to the total uncertainty, which will be the subject of the following section dedicated to the sensitivity analysis.

\section{Sensitivity analysis}

The goal of the sensitivity analysis is to evaluate the contribution of the different uncertainty sources (related to the hazard, vulnerability and loss models) to the total uncertainty. For this purpose we analyse and compare the results of computations obtained following different branches of the logic tree (Fig. 1) and considering different combinations of the input parameters.

To anatomize the structure of the total uncertainty and determine the contribution of the individual sources related to the hazard component, we calculate the associated hazard curves separately for each of the 45 considered branches of the logic tree, representing different combinations of the input parameters. The obtained results are presented in Fig. 10a, b, where the hazard curves are clearly distinguishable visually. The three sets of different colours represent the 
three considered ground-shaking intensity attenuation models, namely, blue - Stromeyer and Grünthal, 2009 (SG2009), green - Chandler and Lam, 2002 (CM2002), and red - Allen and Wald (2010) (AW2010). Each of these sets includes nine curves, each of which, in turn, represents different combinations of three values of $M_{\max }$ and three $b$ values. The hazard curves calculated for the parameter $M_{\min }=3.8$ (for the relationships of Stromeyer and Grünthal, 2009 and Chandler and Lam, 2002) are presented in Fig. 10a, while Fig. 10b presents the curves calculated for the parameter $M_{\min }=5.0$ (using all three considered intensity prediction equations).

From a comparison of the results, it can be seen that the calculated hazard curves are very sensitive to both the selected intensity prediction equations and the assigned maximum magnitude. The change of the parameter $M_{\max }$ correspondingly changes the level of estimated hazard: increased values of $M_{\max }$ lead to increased hazard and vice versa. The influence of the $b$ value is less noticeable, although it is manifested in an expected way, namely, a change in the $b$ value changes the slope of the hazard curves, where a greater (smaller) $b$ value results in increased (decreased) probabilities of lower (higher) intensities and decreased (increased) probability of higher intensities.

As for the considered intensity prediction equations (IPE), a comparison of the calculated results shows significant differences in the produced outcomes, meaning that the use of the models adapted from other regions may introduce a considerable (and possibly excessive) uncertainty. Furthermore, the models intended for global applications should be treated carefully, especially in regions of low to moderate seismicity. In particular, from a comparison of Fig. 10a and b, where the principal difference is a result of the choice of $M_{\min }$, it can be seen that neglecting the influence of lower magnitude events may cause the underestimation of hazard levels when considering lower intensities (5 to 6 degrees), which represent, however, a measurable damage risk for vulnerable types of buildings.

From the results presented above one may conclude that the main efforts for reducing epistemic uncertainties in hazard calculations should be aimed at refining or selecting the proper ground-shaking intensity attenuation model, and assessing the maximum realistically possible earthquake magnitude in the region.

The further step is to propagate all the above-mentioned uncertainties through the whole chain of the risk analyses to evaluate their relative contribution to the total uncertainty in the risk results. The calculated risk curves in terms of MDR are shown in Fig. 11. These results are obtained by the use of the whole family of the hazard curves and different combinations of the vulnerability models (VMs) and loss models (LMs).

Different curves in Fig. 11a-d correspond to the different branches of the logic tree (Fig. 1) and show the contribution of different input parameters to the calculated results. As stated in the legend, different colours identify five subsets of
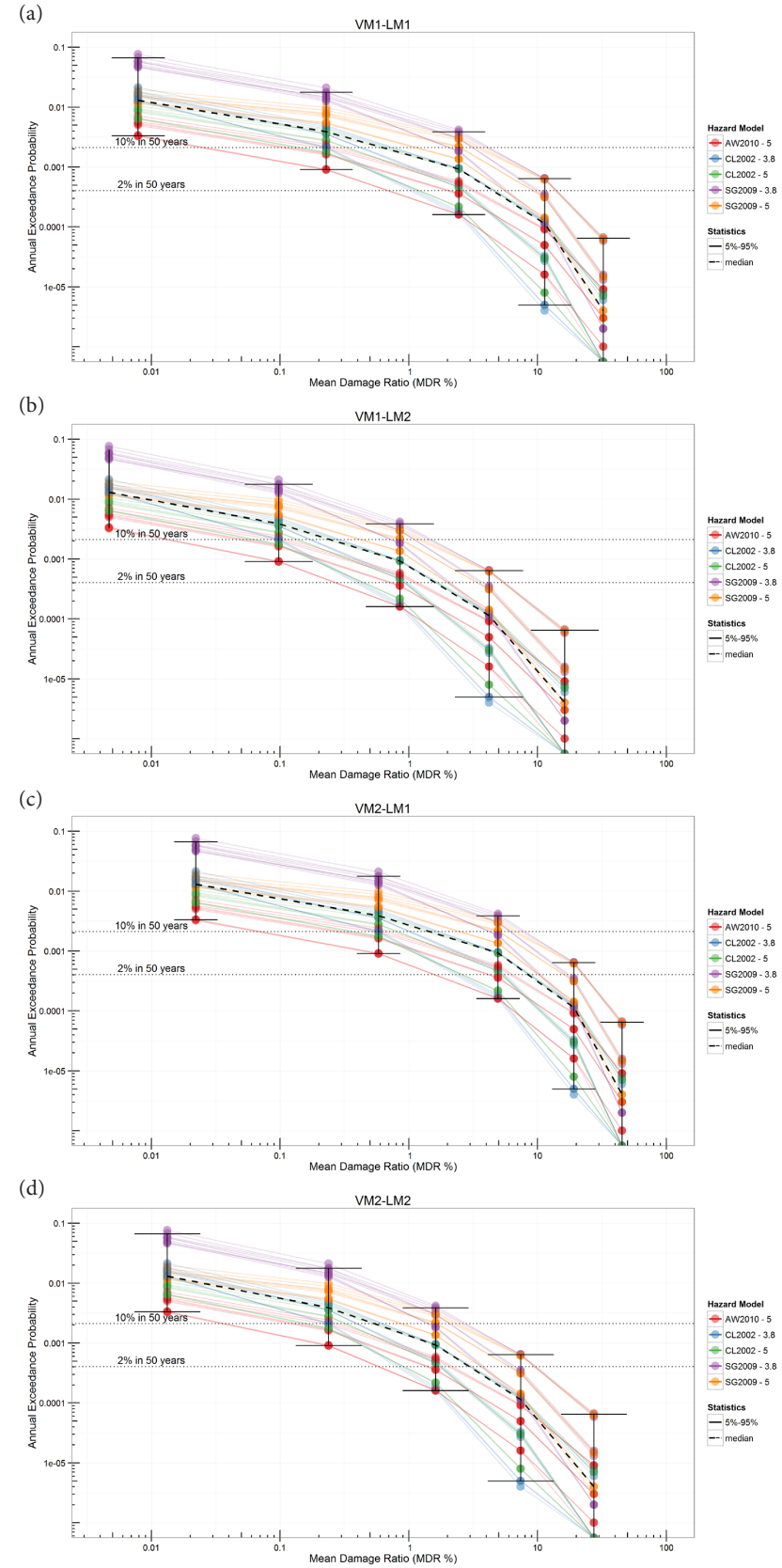

Figure 11. Comparison of the risk curves for different combinations of the vulnerability and loss models: (a) VM1 and LM1, (b) VM1 and LM2, (c) VM2 and LM1, (d) VM2 and LM2.

the curves, representing different combinations of the considered intensity prediction equations: SG2009 (Stromeyer and Grünthal, 2009), CM2002 (Chandler and Lam, 2002), AW2010 (Allen and Wald, 2010) with the parameter $M_{\min }$ $\left(M_{\min }=3.8\right.$ and $\left.M_{\min }=5.0\right)$. Each of the five coloured subsets includes nine curves corresponding to the different combinations of the input variables $M_{\max }$ and $b$ (as considered above, Fig. 10). Additionally, all the graphs show the 5th and 95th percentiles as well as the median risk estimates. A 


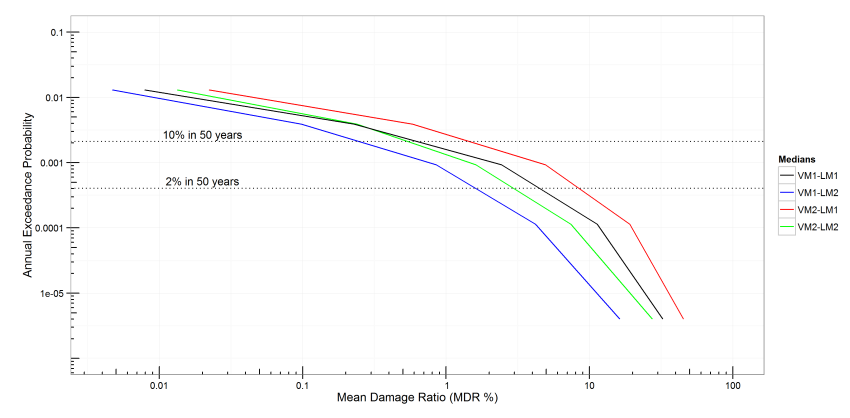

Figure 12. Comparison of the median estimates of seismic risk for the four different combinations of the vulnerability (VM) and loss (LM) models.

comparison of the four median curves corresponding to different combinations of VMs and LMs is presented in Fig. 12.

Analysing the estimates presented in Figs. 11 and 12, we can see that, in general, LM1 gives more conservative estimates in comparison to LM2, as can be expected from a consideration of Table 1. Regarding the comparison of the vulnerability models, as was mentioned above, VM2 gives, in general, more conservative estimates than VM1.

The presented results show a considerable scatter in the risk estimates and one can see that the contribution of the uncertainty related to the vulnerability and loss models to the total uncertainty can be significant and, therefore, should be taken into consideration. Quantitatively, for the considered models, the contributions of uncertainties related to the vulnerability component and to the loss component are comparable. At the same time, a comparison of the presented results shows that the greatest contribution to the total uncertainty originates from the hazard component.

\section{Monetary losses}

For the estimation of the level of risk in terms of monetary losses, we can combine the risk estimates obtained in terms of mean damage ratio (Fig. 9) with the values of the assets at risk, e.g. construction costs. For this purpose, we use the results of Kleist et al. (2006), where the construction costs were estimated for residential buildings in different communities of Germany. For the year 2000, the level of construction costs for the residential building stock of Cologne was EUR 49176 per person. Using this per capita value and the total number of inhabitants in the community, which is 1017155 (for the reference year 2011, Kommunalprofil Köln, 2012), we can roughly estimate the total exposure in terms of the cost of the residential building stock in Cologne and, assuming the uniform distribution of assets, calculate the risk in terms of the corresponding monetary losses. We should keep in mind that the mentioned assumptions reflect additional uncertainties related to the value and the spatial distribution of assets

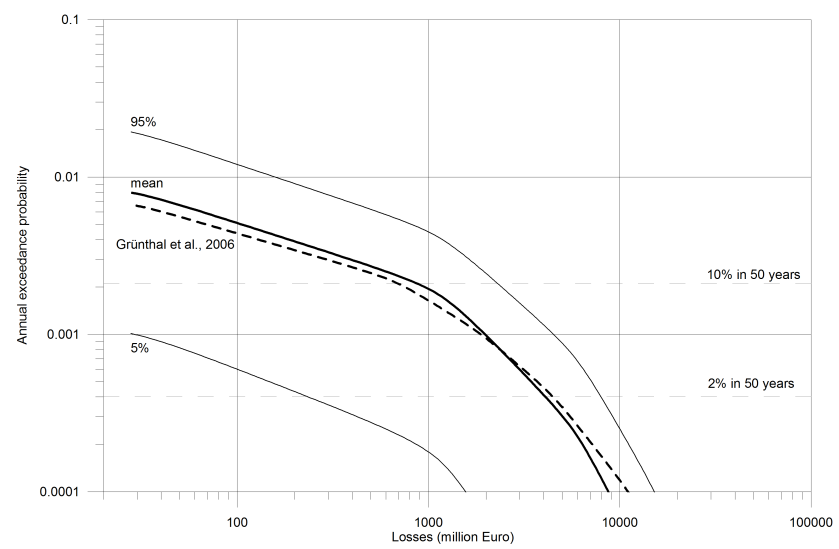

Figure 13. Seismic risk curves in terms of monetary losses (millions of Euros) due to structural damage to the residential building stock in Cologne (mean and 5-95\% percentiles). The dashed line shows the mean risk curve from the study of Grünthal et al. (2006), which also included the damage to commercial and industrial buildings.

at risk in the area under study. However, considering these uncertainties is beyond the scope of the current study.

The calculated risk curves (mean and percentiles 5 and $95 \%)$ are shown in Fig. 13. In addition, for comparison, Fig. 13 shows the mean seismic risk curve for Cologne obtained within the framework of the first multiple risk study in the area (Grünthal et al., 2006), where different natural risks (earthquakes, floods, windstorms) were estimated and compared. In that study, however, only mean risk curves without uncertainties were presented.

It can be seen from Fig. 13 that the mean seismic risk curves for both studies are comparable, although in the range of higher probabilities, corresponding to shorter return periods/lower levels of seismic hazard, our study gives slightly higher loss estimates, whereas for the lower probability events, corresponding to longer return periods/higher levels of seismic hazard (higher than intensity VII-VIII), our risk estimates are relatively lower. This difference can be explained by the differences in the models used, including the fact that our study considered the losses due to the damage to residential buildings only, while the loss estimates of the study of Grünthal et al. (2006) also included the damage to commercial and industrial buildings.

Consideration of other earthquake loss studies conducted for the area of Cologne in the past years can also illustrate the importance of thorough uncertainty analyses in risk assessments. For example, Allmann et al. (1998) estimated the loss potentials for three hypothetical earthquake scenarios near Cologne: $M=6,10 \mathrm{~km} ; M=6.4,10 \mathrm{~km}$, and $M=6.7,15 \mathrm{~km}$, which gave losses of USD 14.5, 55 and 106 billion, respectively, although the occurrence probability of these events was not indicated by the authors. In the publication of Tyagunov et al. (2006a), where the earthquake damage to only residential building stock was considered, 
the economic losses for Cologne were estimated to be of the order of EUR 790 million. These estimates were calculated for the hazard level VI-VII (EMS), corresponding to a mean return period of 475 years. Daniell and Wenzel (2011) estimated loss potential for a scenario event with a magnitude $M=5.7-5.8$ at the Erft fault system, representing a mean return period of approximately 1500 years and producing mean intensity of 7.16 (MMI) in Cologne. For the community of Cologne, the estimated losses reached EUR 2827 billion (for residential buildings) and EUR 6185 billion (total losses).

Figure 13 shows how large the influence of uncertainties can be to the risk estimation results, depending upon the quality of the used models and input parameters. In particular, for the range of input parameters considered in the present study (including the hazard, vulnerability and loss models), the output loss estimates within the interval of 5 and $95 \%$ may vary by about two orders of magnitude for the $2 \%$ exceedance probability in 50 years and even larger for the $10 \%$ exceedance probability in 50 years. In monetary terms, this means that the loss estimates may range from millions to billions of euro. It should be noted that all the above-mentioned estimates of loss potentials obtained by other authors also lie within the indicated range of uncertainty bounds. This case study therefore emphasizes the importance of the identification, evaluation and reduction of existing uncertainties for the sake of sound decision making. At the same time, we must bear in mind that the uncertainty bounds shown in Fig. 13 should not be regarded as a quantitative estimation for the specific case of Cologne, but rather they serve as an illustration within the context of less well studied areas.

\section{Conclusions}

Considering the example of and with reference to the conditions of Cologne, we have implemented uncertainty and sensitivity analyses in seismic risk assessment. The study focused on considering the epistemic (reducible) part of the uncertainty. Using the logic tree approach for the analysis of the uncertainty and sensitivity of the output results with respect to different input components (branches of the logic tree), we considered different parameters related to hazard, vulnerability and loss models. For the sensitivity analysis, we considered a set of input parameters and models, some of which are based on regional data and others adapted from other regions.

The aim of this study is neither the revision, nor refinement of the hazard and risk level for Cologne; rather, it is concerned with investigating and emphasizing how large existing uncertainties can be, even for areas that might in fact be considered to be well studied. Therefore, the obtained results aim to shed light on how high the uncertainty level can be in little-studied areas, where hazard and risk models are based on data adapted from other regions of the globe, and how the uncertainties can influence the hazard and risk estimates.

For the considered set of input parameters, including hazard, vulnerability and loss models, the greatest contribution to the total uncertainty comes from the hazard part (mainly from the assigned maximum magnitudes and selected intensity prediction equations). However, the contribution from the vulnerability and loss models to the total uncertainty may also be substantial and, therefore, should be taken into consideration for the increased efficiency of the decision-making process. In particular, it should be emphasized that the use of the models adapted from other regions may introduce a considerable uncertainty; therefore, they are subject to restriction (or to be used with much smaller weights than the regional models, if the latter are available).

The major efforts required for reducing epistemic uncertainties in hazard calculations should be directed, first of all, towards selecting the proper ground-shaking intensity attenuation model and assessing the realistic maximum possible earthquake magnitude in the region. Reducing the epistemic uncertainty in exposure and vulnerability modelling can be achieved through the collection of detailed information about the spatial distribution of different building types, including the development of building-type-specific vulnerability (fragility) functions. For reducing epistemic uncertainty related to loss modelling, it is advisable to develop and apply building-type-specific loss functions, based on typical regional construction practices. The use of regional knowledge-based information for assigning weights to the different models (branches of the logic tree) would reduce the total uncertainty in the calculated results.

In the end, it is important to note once again that in this study for the example of Cologne along with the original data available from the area, we intentionally used models adapted from other regions with equal weights for both the regional and adapted models, keeping in mind the lack of knowledge which is the usual case for less well studied areas. The resulting uncertainty bounds should therefore not be regarded as a definitive quantitative estimation of uncertainty for the specific case of Cologne, which in any case was not the goal of this study.

Acknowledgements. The research leading to these results has received funding from the European Community's Seventh Framework Programme [FP7/2007-2013] under grant agreement no. 265138.

The authors would like to thank Gottfried Grünthal for providing the input data for seismic hazard calculations and valuable scientific discussions. We are grateful to the GEM facility team for developing and providing the OpenQuake code and, in particular, to Damiano Monelli for helping with the practical application of the software.

We thank the municipality of Cologne for providing the cadastral data. 
The authors would also like to thank the reviewers, whose comments have helped to improve the quality of this article.

The service charges for this open access publication have been covered by a Research Centre of the Helmholtz Association.

Edited by: T. Glade

Reviewed by: three anonymous referees

\section{References}

Allen, T. I. and Wald, D. J.: Prediction of macroseismic intensities for global active crustal earthquakes, in:"Best practices" for using macroseismic intensity and ground motion intensity conversion equations for hazard and loss models in GEM1, edited by: Cua, G., Wald, D. J., Allen, T. I., Garcia, D., Worden, C. B., Gerstenberger, M., Lin, K., and Marano, K., GEM Technical Report 2010-4, 2010.

Allmann, A., Rauch, E., and Smolka, A.: New paleoseismological findings on major earthquakes in Central Europe: Possible consequences for the earthquake potential in Germany. Proceedings 11th European Conf. Earthquake Eng. Rotterdam: Balkema, 1998.

Atakan, K., Ojeda, A., Camelbeeck, T., and Megraoui, M.: Seismic hazard analysis results for the Lower Rhine Graben and the importance of paleoseismic data, Geologie en Mijnbouw, 80, 305314, 2001.

Aven, T. and Zio, E.: Some considerations on the treatment of uncertainties in risk assessment for practical decision making, Reliabil. Eng. Syst. Safety, 96, 64-74, 2011.

Baker, J. W. and Cornell, C. A.: Uncertainty Propagation in Probabilistic Seismic Loss Estimation, Struct. Safety, 30, 236-252, 2008.

Bayraktarli, Y. Y., Baker, J. W., and Faber, M. H.: Uncertainty treatment in earthquake modeling using Bayesian probabilistic networks, GeoRisk, 5, 44-58, 2011.

Bazzurro, P. and Luco, N. Accounting for uncertainty and correlation in earthquake loss estimation, Proceedings of the 9th International Conference on Structural Safety and Reliability (ICOSSAR), Rome, Italy, 2687-2694, 2005.

Bertz, G.: Assessment of the losses caused by the 1992 Roermond earthquake, The Netherlands, Geologie en Mijnbouw, 73, p. 281, 1994.

Bommer, J. J. and Scherbaum, F.: The Use and Misuse of Logic Trees in Probabilistic Seismic Hazard Analysis, Earthquake Spec., 24, 997-1009, 2008.

Bommer, J. J., Scherbaum, F., Bungum, H., Cotton, F., Sabetta, F., and Abrahamson, N.A.: On the Use of Logic Trees for GroundMotion Prediction Equations in Seismic Hazard Analysis, B. Seismol. Soc. Am., 95, 377-389, 2005.

Bradley, B. A. and Lee, D. S.: Accuracy of approximate methods of uncertainty propagation in seismic loss estimation, Struct. Safety, 32, 13-24, 2010.

Buratti, N., Ferracuti, B., Savoia, M., Antonioni, G., and Cozzani, V.: A Fuzzy-Sets Based Approach for Modelling Uncertainties in Quantitative Risk Assessment of Industrial Plants Under Seismic Actions, Chem. Eng. Trans., 26, 105-110, 2012.
Camelbeeck, T., Alexandre, P., Vanneste, K., and Meghraoui, M.: Long-term seismicity in regions of present day low seismic activity: the example of Western Europe, Soil Dynam. Earthq. Eng., 20, 405-414, 2000.

Camelbeeck, T., Vanneste, K., Alexandre, P., Verbeeck, K., Petermans, T., Rosset, P., Everaerts, M., Warnant, R., and Van Camp, M.: Relevance of active faulting and seismicity studies to assessments of long-term earthquake activity and maximum magnitude in intraplate northwest Europe, between the Lower Rhine Embayment and the North Sea, Geol. Soc. Am., Special Paper 425, 193-224, 2007.

Chandler, A. M. and Lam, N. T. K.: Intensity attenuation relationship for the South China region and comparison with the component attenuation model, J. Asian Eart. Sci., 20, 775-790, 2002.

Chen, H. and Sun, B.: Study on Loss Ratio of Urban Building Damages, Proceedings of the 14th World Conference on Earthquake Engineering, 12-17 October 2008, Beijing, China, 2008.

Cornell, C. A.: Engineering seismic risk analysis, B. Seismol. Soc. Am., 58, 1583-1606, 1968.

Cramer, C. H., Petersen, M. D., and Reichle, M. S.: A Monte Carlo approach in estimating uncertainty for a seismic hazard assessment of Los Angeles, Ventura, and Orange counties, California, B. Seismol. Soc. Am., 86, 1681-1691, 1996.

Crowley, H., Bommer, J., Pinho, R., and Bird, J.: The impact of epistemic uncertainty on an earthquake loss model, Earthquake Eng. Struct. Dynam., 34, 1653-1685, 2005.

Crowley, H., Monelli, D., Pagani, M., Silva, V., and Weatherill, G.: OpenQuake User's Manual, available at: www. globalquakemodel.org (last access: 30 May 2012), 2011a.

Crowley, H., Monelli, D., Pagani, M., Silva, V., and Weatherill, G.: OpenQuake Book, available at: www.globalquakemodel.org (last access: 30 May 2012), 2011b.

de Rocquigny, E.: Modelling Under Risk and Uncertainty: An Introduction to Statistical, Phenomenological and Computational Methods, in: Wiley Series in Probability and Statistics, John Wiley \& Sons, Ltd, Chichester, UK, 2012.

Daniell, J. E. and Wenzel, F.: Deterministic Earthquake Scenarios for the Northern Rhine Region, 12. D-A-CH Tagung - Erdbeben und Baudynamik, Hannover, Deutschland, 15-16 September 2011, DGEB Publikation 2011-01, 13-24, 2011.

Deutsche Gebäudetypologie: Systematik und Datensätze, Institut Wohnen und Umwelt GmbH, Darmstadt, 2005.

Douglas, J.: Physical vulnerability modelling in natural hazard risk assessment, Nat. Hazards Earth Syst. Sci., 7, 283-288, doi:10.5194/nhess-7-283-2007, 2007.

Field, E. H., Jordan, T. H., and Cornell, C. A.: OpenSHA - A developing Community-Modeling Environment for Seismic Hazard Analysis, Seismol. Res. Lett., 74, 406-419, 2003.

Grünthal, G.: European Macroseismic Scale 1998, Cahiers du Centre Europeen de Geodynamique et de Seismologie, Vol. 15, Conseil de l'Europe, Luxembourg, 99, 1998.

Grünthal, G. and Wahlström, R.: Sensitivity of Parameters for Probabilistic Seismic Hazard Analysis Using a Logic Tree Approach, J. Earthquake Eng., 5, 309-328, 2001.

Grünthal, G. and Wahlström, R.: New Generation of Probabilistic Seismic Hazard Assessment for the Area Cologne/Aachen Considering the Uncertainties of the Input Data, Nat. Hazards, 38, 159-176, 2006. 
Grünthal, G., Thieken, A. H., Schwarz, J., Radtke, K. S., Smolka, A., and Merz, B.: Comparative Risk Assessments for the City of Cologne - Storms, Floods, Earthquakes, Nat. Hazards, 38, 2144, 2006.

Grünthal, G., Wahlström, R., and Stromeyer, D.: The unified catalogue of earthquakes in central, northern, and northwestern Europe (CENEC) - updated and expanded to the last millennium, J. Seismol, 13, 517-541, 2009.

Grünthal, G., Arvidsson, R., and Bosse, Ch.: Earthquake Model for the European-Mediterranean Region for the Purpose of GEM1, Scientific Technical Report SRT10/04, GFZ, 36, 2010.

Hinzen, K.-G. and Reamer, S. K.: Seismicity, seismotectonics, and seismic hazard in the northern Rhine area, Geol. Soc. Am., Special Paper 425, 225-242, 2007.

Hwang, H. M., Xu, M., and Huo, J.-R.: Estimation of Seismic Damage and Repair Cost of the University of Memphis Buildings, Memphis, Tennessee, 1994.

INFAS: Database Das DataWherehouse, Bonn, INFAS GEOdaten GmbH, 2001.

INFAS: Database Das DataWherehouse, Bonn, INFAS GEOdaten $\mathrm{GmbH}, 2010$.

ISDR: UNISDR Terminology on Disaster Risk Reduction, United Nations International Strategy for Disaster Reduction (UNISDR), Geneva, Switzerland, May, 2009.

Karimi, I. and Hüllermeier, E.: Risk assessment system of natural hazards: A new approach based on fuzzy probability, Fuzzy Sets Syst., 158, 987-999, 2007.

Kircher, C. A., Reitherman, R. K., Whitman, R. V., and Arnold, C.: Estimation of Earthquake Losses to Buildings, Earthquake Spect., 13, 703-720, 1997.

Kleist, L., Thieken, A. H., Köhler, P., Müller, M., Seifert, I., Borst, D., and Werner, U.: Estimation of the regional stock of residential buildings as a basis for a comparative risk assessment in Germany, Nat. Hazards Earth Syst. Sci., 6, 541-552, doi:10.5194/nhess-6-541-2006, 2006.

Kommunalprofil Köln: Information und Technik NordrheinWestfalen, Geschäftsbereich Statistik, available at: http://www. it.nrw.de (last access: 30 May 2012), 2012.

Li, L., Wang, J., and Leung, H.: Using spatial analysis and Bayesian network to model the vulnerability and make insurance pricing of catastrophic risk, Int. J. Geogr. Inform. Sci., 24, 1759-1784, 2010.

Liel, A., Haselton, C., Deierlein, G. G., and Baker, J.W.: Incorporating modeling uncertainties in the assessment of seismic collapse risk of buildings, Struct. Safety, 31, 197-211, 2009.

McGuire, R. K.: FORTRAN computer program for seismic risk analysis, Open-File Report 76-67, United States Department of the Interior, Geological Survey, 102, 1976.

McGuire, R. K.: Seismic Risk Mitigation Decisions Under Uncertainty, in: Risk Assessment, Modeling and Decision Support, Strategic Directions, edited by: Bostrom, A., French, S. P., and Gottlieb, S. J., 2008.

Miyakoshi, J., Hayashi, Y., Tamura, K., and Fukuwa, N.: Damage ratio functions of buildings using damage data of the 1995 Hyogo-Ken Nanbu earthquake, Proceedings of the 7th International Conference on Structural Safety and Reliability (ICOSSAR '97), Vol. 1, 349-354, Kyoto, Japan, 1997.
Molina, S. and Lindholm, C. D.: Estimating the confidence of earthquake damage scenarios: examples from a logic tree approach, J. Seismol., 11, 299-310, 2007.

Musson, R. M. W.: Intensity-based seismic risk assessment, Soil Dynam. Earthquake Eng., 20, 353-360, 2000.

Nadim, F.: Tools and Strategies for Dealing with Uncertainty in Geotechnics, in: Probabilistic Methods in Geotechnical Engineering, edited by: Griffiths, D. V. and Fenton, G. A., CISM Courses and Lectures, Vol. 491, 71-95, 2007.

Padgett, J. and DesRoches, R.: Sensitivity of Seismic Response and Fragility to Parameter Uncertainty, J. Struct. Eng., 133, 1710 1718, 2007.

Parolai, S., Grünthal, G., and Wahlström, R.: Site-specific response spectra from the combination of microzonation with probabilistic seismic hazard assessment - An example for the Cologne (Germany) area, Soil Dynam. Earthquake Eng., 27, 49-59, 2007.

Paté-Cornell, E.: Risk and uncertainty analysis in government safety decisions, Risk Anal., 22, 633-646, 2002.

Rosenhauer, W. and Ahorner, L.: Seismic hazard assessment for the Lower Rhine Embayment before and after the 1992 Roermond earthquake, Geol. Mijnbouw, 73, 415-424, 1994.

Saltelli, A., Ratto, M., Andres, T., Campolongo, F., Cariboni, J., Gatelli, D. Saisana, M., and Tarantola, S.: Global Sensitivity Analysis. The Primer, John Wiley \& Sons, 2008.

Scherbaum, F., Bommer, J. J., Bungum, H., Cotton, F., and Abrahamson, N. A.: Composite Ground Motion Models and Logic Trees: Methodology, Sensitivities and Uncertainties, BSSA, 95, 1575-1593, 2005.

Schmedes, J., Hainzl, S., Reamer, S. K., Scherbaum, F., and Hinzen, K.-G.: Moment release in the Lower Rhine Embayment, Germany: seismological perspective of the deformation process, Geophys. J. Int., 160, 901-909, 2005.

Schwarz, J., Langhammer, T., Maiwald, H., and Smolka, A.: Comparative seismic risk studies for German earthquake regions damage and loss assessment for the city of Cologne, in: Proceedings of the 13th World Conference on Earthquake Engineering, Vancouver, Canada, Paper 238, 2004a.

Schwarz, J., Maiwald, H., and Raschke, M.: Erdbebenszenarien fur deutsche Großstadträume und Quantifizierung der Schadenpotentiale, in: Deutsches Forschungsnetz Naturkatastrophen (DFNK) Abschlussbericht, edited by: Merz, B. and Apel, H., 188-200, 2004b.

Schwarz, J., Raschke, M., and Maiwald, H.: Comparative Seismic Risk Studies for German Earthquake Regions on the Basis of the European Macroseismic Scale EMS-98, Nat. Hazards, 38, 259282, 2006.

Smith, W. D.: Earthquake hazard and risk assessment in New Zealand by Monte Carlo methods, Seismol. Res. Lett., 74, 298304, 2003.

Sokolov, V. and Wenzel, F.: Influence of ground-motion correlation on probabilistic assessments of seismic hazard and loss: sensitivity analysis, Bull. Earthquake Eng., 9, 1339-1360, 2011.

SSHAC (Senior Seismic Hazard Analysis Committee): Recommendations for Probabilistic Seismic Hazard Analysis: Guidance on Uncertainty and Use of Experts, U.S. Nuclear Regulatory Commission, NUREG/CR-6372, Washington, DC, 1997.

Stadt Köln: mit Genehmigung des Amtes für Liegenschaften, Vermessung und Kataster, Katasterservice 232-4 der Stadt Köln, GSB-Nr.: ED 5197/2011, 2012. 
Stromeyer, D. and Grünthal, G.: Attenuation relationship of macroseismic intensities in Central Europe, Bull. Seismol. Soc. Am., 99, 554-565, 2009.

Taubenböck, H., Esch, T., Felbier, A., Wiesner, M., Roth, A., and Dech, S.: Monitoring urbanization in mega cities from space, Remote Sens. Environ., 117, 162-176, 2012.

Thywissen, K.: Components of Risk: A comparative glossary, SOURCE Publication Series of UHU-EHS, 2/2006, 52 pp., 2006.

Tyagunov, S., Hollnack, D., and Wenzel, F.: Risiken durch Sekundäreffekte von Erdbeben, Deutsches Forschungsnetz Naturkatatrophen (DFNK) Abschlussbericht, edited by: Merz, B. and Apel, H., GeoForschungsZentrum Potsdam, 179-187, 2004.

Tyagunov, S., Grünthal, G., Wahlström, R., Stempniewski, L., and Zschau, J.: Seismic risk mapping for Germany, Nat. Hazards Earth Syst. Sci., 6, 573-586, doi:10.5194/nhess-6-573-2006, 2006a.

Tyagunov, S., Grünthal, G., Wahlström, R., Stempniewski, L., and Zschau, J.: Building stock vulnerability modeling for earthquake damage and loss assessment, First European Conference on Earthquake Engineering and Seismology, Geneva, Switzerland, 2006b.

Vanneste, K., Camelbeeck, T., and Verbeeck, K.: A Model of Composite Seismic Sources for the Lower Rhine Graben, Northwest Europe, Bull. Seismol. Soc. Am., 103, 984-1007, 2013.

Verbeeck, K., Vanneste, K., and Camelbeeck, T.: Seismotectonic zones for probabilistic seismic-hazard assessment in Belgium, NIROND TR-2008-31 E ONDRAF/NIRAS Technical Report 47, 2009.
Wang, X., He J., Ding, X., and Wang, Y.: A Review of the Study on Uncertainty of Earthquake Loss Estimation, Earthquake Res. China, 23, 310-318, 2009.

Wen, Y. K., Ellingwood, B. R., Veneziano, D., and Bracci, J.: Uncertainty Modeling in Earthquake Engineering, Report FD-2, MidAmerica Earthquake Center, University of Illinois at UrbanaChampaign, available at: http://mae.ce.uiuc.edu, 2003.

Wesson, R. L., Perkins, D. M., Luco, N., and Karaca, E.: Direct Calculation of the Probability Distribution for Earthquake Losses to a Portfolio, Earthquake Spec., 25, 687-706, 2009.

Wieland, M., Pittore, M., Parolai, S., Zschau, J., Moldobekov, B., and Begaliev, U.: Estimating building inventory for rapid seismic vulnerability assessment: Towards an integrated approach based on multi-source imaging, Soil Dynam. Earthquake Eng., 36, 7083, 2012.

Whitman, R. and Cornell C. A.: Design, in: Seismic risk and engineering decisions, edited by: Lomnitz, C. and Rosenblueth, E., Elsevier, Amsterdam - Oxford - New York, 1976.

Zentner, I., Nadjarian, A., Humbert, N., and Viallet, E.: Numerical calculation of fragility curves for probabilistic seismic risk assessment, Proceedings of the 14th World Conference on Earthquake Engineering, 12-17 October 2008, Beijing, China, 2008.

Zlateva, P., Pashova, L., Stoyanov, K., and Velev, D.: Social Risk Assessment from Natural Hazards Using Fuzzy Logic, Int. J. Soc. Sci. Human., 1, 193-198, 2011. 